\title{
Polymerization and Characterization Technique of Pavement Reinforcement Geopolymer Cementitious Material
}

\author{
Zhang lei ${ }^{1, a^{*}}$,Wang hailiang ${ }^{2, b}$ and Guo jin ${ }^{3, c}$ \\ ${ }^{1}$ School of Highway, Chang'an University, Xi'an, Shaanxi Province, China \\ ${ }^{2}$ School of Highway, Chang'an University, Xi'an, Shaanxi Province, China \\ ${ }^{3}$ School of Highway, Chang'an University, Xi'an, Shaanxi Province, China

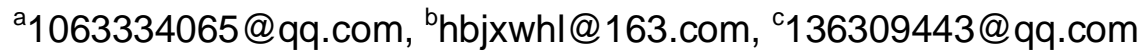

Keywords: Geopolymer; Cementitious material; Polymerization; Characterization technique.

Abstract. Application of ground polymer cementitious material can reduce resource consumption and environmental pollution. Chemical composition and polymerization mechanism were analyzed, in order to promote the research and application of the polymer materials. Technology principle of Isothermal conduction calorimetry, dynamic rheological test, environmental scanning electron microscopy, electron paramagnetic resonance imaging and total reflection Fourier infrared spectrometry were introduced, and the applicability of these methods to research on the material of ground - polymer gel were determined.

\section{Introduction}

Lots of resources,energy and great pollution can be consumed by traditional silicate cement industry production.Geopolymer,a new type of "green building material",whose engineering properties similar to the traditional Portland cement's, and abundant raw materials, simple process, low cost and energy saving.

In this paper,the chemical composition and polymerization reaction mechanism of the material are analyzed.Introducing the technology principles of Isothermal conduction calorimetry,Dynamic rheological testing method,Environmental sem method,Electron paramagnetic resonance technique and Total reflection Fourier infrared spectroscopic analysis, and applications of the study field of geopolymer cementitious material.

\section{Chemical composition and reaction mechanism of the polymer}

Chemical composition of geopolymer. Geopolymer is a kind of three dimensional framwork inorganic polymer composed of $\mathrm{AlO}_{4}$ and $\mathrm{SiO}_{4}$ tetrahedral structure elements, and is nonfixiform semi-crystalline. And it belongs non metallic materials.

With low temperature $\left(500 \sim 900^{\circ} \mathrm{C}\right)$ calcination, the kaolin minerals generated in the metastable state metakaolin, and in the interaction of alkaline activator and hardening accelerating admixture,forming the geopolymer cementitious material.At this point, the silicon aluminoxy in the raw materials experienced a depolymerization to polymerization process, forming a structure similar to some natural minerals, the typical chemical composition see Table 1.

Table 1 The main mineral components of the geopolymer cementitious material and two kinds of natural minerals [\%]

\begin{tabular}{cccccc}
\hline materials & $\mathrm{SiO}_{2}$ & $\mathrm{Al}_{2} \mathrm{O}_{3}$ & $\mathrm{CaO}$ & $\mathrm{MgO}$ & $\mathrm{K}_{2} \mathrm{O}+\mathrm{Na}_{2} \mathrm{O}$ \\
\hline PZ type geopolymer & 59.1 & 17.5 & 11.0 & 3.0 & 9.2 \\
cementitious material & 53.9 & 18.9 & 10.2 & 1.5 & 10.7 \\
Italian pozzolanic & 57.1 & 20.1 & 5.8 & 2.0 & 7.1 \\
Rhenish pozzolanic & & &
\end{tabular}

Table 1 shows that the geopolymer mineralogical composition is composed of nonfixiform minerals: metakaolin (components is shown in Table 2); the alkaline activator(Potassa,Caustic 
soda,Sodium silicate, Potassium silicate,etc); hardening accelerating admixture (low $\mathrm{Ca} / \mathrm{Si}$ ratio of calcium silicate and silica fume, In an indefinite form); admixture (mainly retarder,etc) ${ }^{[1]}$.

Table 2 Chemical composition metakaolin [\%]

\begin{tabular}{cccccccccc}
\hline $\mathrm{SiO}_{2}$ & $\mathrm{Al}_{2} \mathrm{O}_{3}$ & $\mathrm{Fe}_{2} \mathrm{O}_{3}$ & $\mathrm{CaO}$ & $\mathrm{TiO}_{2}$ & $\mathrm{MnO}$ & $\mathrm{K}_{2} \mathrm{O}$ & $\mathrm{P}_{2} \mathrm{O}_{5}$ & I.L. & $\sum$ \\
\hline 53.33 & 43.54 & 0.34 & 0.24 & 0.18 & 0.01 & 0.18 & 0.32 & 1.18 & 99.32 \\
\hline
\end{tabular}

The mechanism of the geopolymer polymerization. To geopolymer synthesis process, first carry out a depolymerization process,namely in acid or alkali excitation conditions, aluminosilicate silicon oxygen bonds and Al-O bond fracture,forming oligomeric silica aluminum tetrahedral;and then carries out a polycondensation process,namely oligomeric aluminosilicate with water medium are recombined,excess water is discharged,generate new Si-O-Al network structure system.

Dr Davidovits gived the chemical structural formula of polymerisation macromolecule,as follows:

$$
\mathrm{Mn}\left\{-\left(\mathrm{SiO}_{2}\right)_{z}-\mathrm{AlO}_{2}\right\} n \bullet \mathrm{wH}_{2} \mathrm{O}
$$

Among them, $\mathrm{M}$ represents the cation, such as $\mathrm{Na}+, \mathrm{K}+; \mathrm{n}$ as the degree of polymerization; $\mathrm{Z}$ for $\mathrm{Si}$ / $\mathrm{Al}$ ratio, whose value takes $1,2,3 ; \mathrm{w}$ is the number of chemical combined water.The structure of the end product of the product is divided into 3 categories,namely PS,PSS,PSDS[2], as follows:

Single silicon aluminum polymer Poly(sialate)

Double silicon aluminum polymer Poly(sialate - siloxo)

Triple silicon aluminum polymer Poly(sialate - disiloxo)

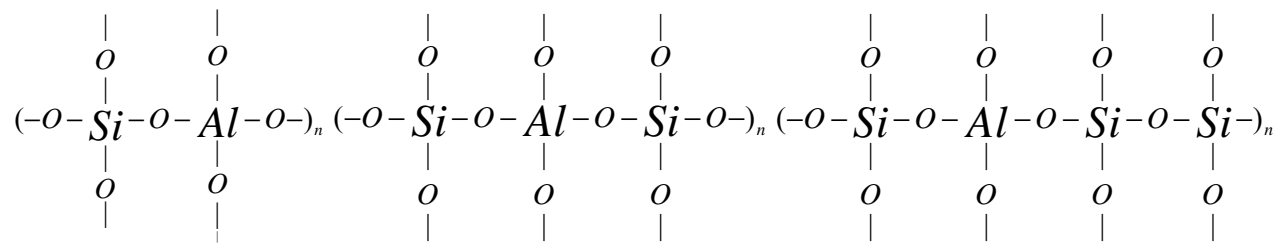

PS Type

PSS Type

PSDS Type

The mechanism of the geopolymer polymerization is as follows (the metakaolin and $\mathrm{NaOH}$ as $\mathrm{raw}$ materials,preparation for Na-PSS).

The first step, metakaolin in water, sodium silicate and alkali $\mathrm{NaOH}$, silicon oxygen bonds and Al-O bonds was breaked and generated positive aluminum silicate, alkali metal ions $\mathrm{Na}+$ adsorption in positive silicate aluminum molecular bonds, balance the negative charge, the reaction equation as formula (1).

$$
\begin{gathered}
\left(\mathrm{Si}_{2} \mathrm{O}_{3}, \mathrm{Al}_{2} \mathrm{O}_{3}\right)_{n}+\mathrm{wSiO}_{2}+\mathrm{H}_{2} \mathrm{O} \stackrel{\mathrm{NaOH}}{\longrightarrow} 2 n(\mathrm{OH})_{3}-\mathrm{Si}-\mathrm{O}-\underset{\substack{\mathrm{I} \\
\text { (OH })_{2}}}{\stackrel{(-)}{\mathrm{Al}}-\mathrm{O}-\mathrm{Si}-(\mathrm{OH})_{3}(1)} \\
\text { (metakaolin) } \quad \text { (positive aluminum silicate) }
\end{gathered}
$$

Second step,on the base of the alkali excitation condition, the hydroxyl group in the positive silicate aluminum moleculeon is converted to hydrogen bond,and the hydroxyl group and hydrogen bond will make dehydration, a large aluminum silicate molecule NaPSS formed,reaction equation as formula (2).

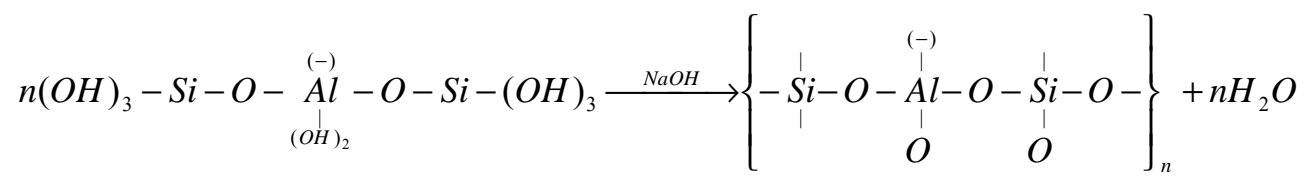

(positive aluminum silicate)

(Na-PSS type geopolymer)

The end product of this process is depended on the first step reaction,in the first step: When the coefficient $\mathrm{w}$ of $\mathrm{SiO}^{2}$ is 0 , the final product is Na-PS; When the coefficient $\mathrm{w}$ of $\mathrm{SiO}^{2}$ is 2 , the final product is Na-PSS; When the coefficient $\mathrm{w}$ of $\mathrm{SiO}_{2}$ is $4 \mathrm{n}$, the final product is Na-PSDS.

It can be inferred from the above reaction process that the majority of aluminosilicate containing raw materials can be prepared geopolymer materials.Current researches are based on the theory of "Depolymerization-Polycondensation", after the akali excitation,aluminum silicate generate 
transition product(positive aluminum silicate), and aluminum silicate polymerize to form geopolymer.

\section{Characterization technique of Geopolymer Polymerization}

Characterization technique of Geopolymer Polymerization,in addition to the traditional research methods such as Isothermal conduction calorimetry,Environmental scanning electron microscopy, and recent years, the new advanced characterization techniques have been used to study the early reaction of the geopolymer system,such as Electron paramagnetic resonance and Total reflection Fourier infrared spectroscopic analysis.

Isothermal conduction calorimetry study on geoploymer polymerization dymatics. sothermal conduction calorimetry(ICC), the main instrument used in this method is the Conducted isothermal calorimeter, it can measure the Instantaneous reaction thermal power which is proportional to the reaction rate at constant temperature. The method can be used to describe the whole process of the hydration of Portland cement paste,so ti also can be used to the geopolymer system.

Dynamic rheological testing method study on geoploymer polymerization progress. As a science about studying flow and deformation, Rheology focus on the relationship between force, deformation and time.Application of rheological theory to the research of cement based materials, namely the rheological properties of cement based materials. It reflects the mixture slurry with the hydration of cement, from the viscous plasticity dominated gradually to the development of hardening process based on the viscoelastic ${ }^{[3]}$. With this method, the dynamic reaction of the formation process of the geopolymer can be used to provide a new idea for the study of the early polymerization.

Environmental scanning electron microscopy observing geoploymer polymerization morphology change. Environmental scanning electron microscopy(ESEM) can be used to observe the temperature, pressure, relative humidity and low vacuum degree and reduce the drying damage and vacuum damage. Especially, the observation of the early reaction stage of paste's micro structure which is very sensitive to humidity. Through computer program memorize observation position, more continuous observation can be realized ${ }^{4]}$.

Electron paramagnetic resonance. Electron paramagnetic resonance(EPR) a magnetic resonance technique, originated from the magnetic moment of non paired electrons, can be used to detect the non paired electrons in the material atoms or molecules from the qualitative and quantitative aspects, and to explore the structural characteristics of the surrounding environment. In the chemical and physical reactions, a meaningful structural information and dynamic information of material can be obtained by EPR,these reactions will not be affected.

Total reflection Fourier infrared spectroscopic analysis. Fourier infrared spectroscopy an important method to analyze the structure of the compound.Apply attenuated total reflection(ATR) technique to the Fourier transform infrared spectrometer,produce Fourier transform attenuated total reflection infrared spectrometer(ATR-FTIR).ATR application greatly simplifies the test of some special samples, so that the analysis of the composition of the micro area becomed convenient and quick $^{[5]}$.

\section{Conclusions}

Geopolymer is a kind of three dimensional framwork inorganic polymer composed of $\mathrm{AlO}_{4}$ and $\mathrm{SiO}_{4}$ tetrahedral structure elements,nonfixiform semi-crystalline.It belongs non metallic materials.

The formation process of the geopolymer is that in the alkali excitation the aluminum silicate produce a transition product (Positive aluminum silicate), these aluminum silicate continue to form geololymer.

Depending on different purposes, Characterizations of Geopolymer Polymerization can be Isothermal conduction calorimetry,Dynamic rheological testing method,Environmental scanning electron microscopy,Electron paramagnetic resonance and Total reflection Fourier infrared spectroscopic analysis etc. 


\section{References}

[1] Wu Min,Shi Huisheng.The Geo-Polymerization and Current Research Status of Geopolymeric Cement[J].China Non-Metallic Mining Industry Herald,2007,03:8-13.

[2] Jian Jiacheng, Liu Zheng. Research on Preparation and Application Status of Geopolymers[J], Multipurpose Utilization of Mineral Resources,2014,03:18-22.

[3] ZHANG Xiong, ZHANG Lei. Fly Ash Comprehensive Util (in Chinese), 2013, 04:9-13.

[4] MA Y,HU J,YE G.The pore structure and permeability of alkali activated fly ash[J]. Fuel, 2013, 104:771-780.

[5] HUANG Hongying, YIN Qihe. J Grad Sun Yat-Sen Univ: Nat Sci Med (in Chinese), 2011, 32(1): 20-20. 